\title{
High-Lycopene Tomato Intake Increases Serum Carotenoid Levels but not Biomarkers of Oxidative Stress and Inflammation in Healthy Adults
}

\author{
C.A. Thomson*, ${ }^{1}$, N.R. Stendell-Hollis ${ }^{1}$, J.L. West ${ }^{1}$, E.C. Cussler ${ }^{2}$, L.M. McCune ${ }^{1}$, M. Kroggel ${ }^{3}$, \\ H.J. Kim ${ }^{3,4}$ and C. Kubota ${ }^{3}$
}

${ }^{I}$ Department of Nutritional Sciences and Arizona Cancer Center, University of Arizona, Tucson, Arizona, ${ }^{2}$ Department of Physiology, University of Arizona. Tucson, AZ, ${ }^{3}$ Department of Plant Sciences, University of Arizona. Tucson, AZ and ${ }^{4}$ Present address: Division of Food Function Research, Korea Food Research Institute, Sungnam-si, Gyeongki-do 463746, Korea

\begin{abstract}
Fresh tomatoes higher in lycopene content than standard varieties have recently been designed. We hypothesized that consumption of fresh, high lycopene tomatoes (HEC) for 3-weeks, as compared to standard fresh tomatoes, (LEC) would result in significant increases in serum lycopene and reductions in oxidative stress and inflammation. Forty healthy adult men $(37.5 \%)$ and women $(62.5 \%)$ age $55.3 \pm 4.7$ years $\left(\mathrm{BMI}=25.1 \pm 3.3 \mathrm{~kg} / \mathrm{m}^{2}\right)$ completed this randomized, crossover, controlled tomato intervention. Serum lycopene, oxidative stress (8-OHdG, 8 -iso-PGF2 $\alpha$ ) and inflammation (hsCRP) were assessed. Significant increases were seen in trans- and cis-lycopene (pre- and post-intervention, $P<$ $0.0001)$, with cis-lycopene increasing significantly more during HEC consumption as compared to LEC $(P=0.03)$. No significant changes in 8-OHdG, 8-iso-PGF2 $\alpha$ or hsCRP were demonstrated. Consumption of HEC tomatoes resulted in significant elevations in serum lycopene but not significant reductions in oxidative stress or inflammation in this healthy adult population.
\end{abstract}

\section{INTRODUCTION}

Tomatoes, rich in lycopene, have been associated with chronic disease risk reduction $[1,2]$. Specifically, diets high in tomato-based foods have been associated with modulation of oxidative stress and inflammation, inhibition of the proliferation of several types of cancer, inducement of cell differentiation and possibly suppression of insulin-like growth factors and/or lipid levels [3-5].

One approach to enhance dietary intake of lycopene and therefore support reduced disease incidence is to develop tomatoes with greater lycopene concentration per serving. However, developing the tomato is only half of the answer, in that efforts to evaluate this approach to health promotion must also evaluate the clinical efficacy in humans, thus the call for more translation research, in this case partnering plant and nutrition scientists. Here we describe a randomized, controlled, crossover design study to evaluate the efficacy of a high lycopene tomato to increase serum lycopene levels and reduce oxidative stress and inflammation in healthy adults. The fresh tomato with higher lycopene content was produced using hydroponic greenhouse growing techniques to increase lycopene production (Table 1) [6].

\section{MATERIALS AND METHODOLOGY}

\section{Study Population and Study Design}

Healthy, non-smoking men and women, age 45 to 65 years were recruited for this study. Subjects were excluded if

\footnotetext{
*Address correspondence to this author at the Department of Nutritional Sciences and Arizona Cancer Center, University of Arizona, Tucson, Arizona. Shantz Building Room 328, 1177 E. 4th Street, Tucson, AZ 85724; Tel: (520) 626-1565; Fax: (520) 621-9446;

E-mail: cthomson@u.arizona.edu
}

unwilling/unable: to discontinue all lycopene-rich foods except study-related tomatoes during the study; to discontinue dietary supplements with the exception of a multivitamin mineral supplement and calcium provided by study investigators; to tolerate tomatoes; or to complete study protocol. Further exclusion criteria and study design are illustrated in Fig. (1). This study was approved by the Institutional Review Board, Human Subjects Committee at the University of Arizona.

Following the initial 6-week washout in which food and supplement sources of lycopene were eliminated from the diet, subjects were randomized into the LEC or the HEC tomato feeding subgroups ( $\mathrm{N}=10$ per group; repeated twice to reach total study population of 40 subjects) during which they consumed the LEC or HEC tomato twice daily (200$260 \mathrm{~g} /$ day; providing $\sim 167.18 \mathrm{mg} / \mathrm{d}$ and $\sim 197.40 \mathrm{mg} / \mathrm{d}$ of total carotenoids, respectively) for 3-weeks with one tablespoon of monounsaturated fat $(\sim 15 \mathrm{~g})$ per tomato to promote "standardized" lycopene absorption [7]. Participants consumed the tomatoes alone or with a meal. The initial feeding period was followed by a second 6-week washout period and then crossover to the alternate tomato feeding for the final 3weeks.

\section{Tomato Production and Quality Assurance}

Tomatoes for this research were cultivated in two $280 \mathrm{~m}^{2}$ Controlled Environment Agriculture Program greenhouses at the University of Arizona using a Rockwool-based hydroponic culture system with moderate salt stress to achieve higher lycopene status. Cultivar 'Durinta' was chosen for the study for its good ripening characteristics. Vine-ripened fruits weighing between 100-130 g fresh weights per fruit that visually represented the median group of red fruits were 
Table 1. Select Carotenoid, Phenolics, and Ascorbic Acid Concentrations Per Tomato Type Per Feeding Group (Means \pm SE)

\begin{tabular}{|c|c|c|c|c|c|}
\hline & $\begin{array}{c}\text { Lycopene } \\
(\mathrm{mg} / \mathrm{kg} \text { FW) }\end{array}$ & $\begin{array}{c}\alpha \text {-Carotene } \\
(\mathrm{mg} / \mathrm{kg} \text { FW) }\end{array}$ & $\begin{array}{l}\beta \text {-Carotene } \\
(\mathrm{mg} / \mathrm{kg} \mathrm{FW})\end{array}$ & $\begin{array}{c}\text { Phenolics } \\
\text { (mg/kg FW) }\end{array}$ & $\begin{array}{c}\text { Ascorbic Acid } \\
(\mathrm{mg} / \mathrm{kg} \mathrm{FW})\end{array}$ \\
\hline Feeding Gp 1 & $(n=6)$ & $(\mathrm{n}=2)$ & $(\mathrm{n}=2)$ & $(\mathrm{n}=6)$ & $(n=6)$ \\
\hline HEC & $77.3 \pm 4.0$ & $0.17 \pm 0.01$ & $8.82 \pm 0.30$ & $400 \pm 9.5$ & $240 \pm 6.2$ \\
\hline LEC & $60.8 \pm 1.6$ & $0.09 \pm 0.01$ & $7.20 \pm 0.34$ & $339 \pm 9.7$ & $107 \pm 34.3$ \\
\hline HEC & $53.8 \pm 2.6$ & $0.02 \pm 0.00004$ & $6.77 \pm 0.22$ & $406 \pm 8.3$ & $241 \pm 8.1$ \\
\hline LEC & $45.6 \pm 2.5$ & $0.02 \pm 0.0005$ & $5.39 \pm 0.16$ & $326 \pm 5.8$ & $179 \pm 9.6$ \\
\hline$P^{a}$ & 0.02 & 0.28 & 0.04 & 0.0001 & 0.001 \\
\hline Feeding Gp 3 & $(\mathrm{n}=6)$ & $(n=3)$ & $(\mathrm{n}=3)$ & $(n=3)$ & $(n=3)$ \\
\hline$P^{a}$ & 0.01 & & 0.37 & 0.01 & 0.04 \\
\hline Feeding Gp 4 & $(n=6)$ & $(n=3)$ & $(\mathrm{n}=3)$ & $(n=3)$ & $(n=3)$ \\
\hline HEC & $57.6 \pm 3.4$ & N.D. & $7.54 \pm 0.33$ & $330 \pm 4.2$ & $158 \pm 8.8$ \\
\hline LEC & $49.2 \pm 2.8$ & N.D. & $6.20 \pm 0.28$ & $322 \pm 19.0$ & $146 \pm 10.3$ \\
\hline$P^{a}$ & 0.01 & & 0.04 & 0.67 & 0.42 \\
\hline$P^{b}$ & $0.0001(n=24)$ & $0.09(n=4)$ & $0.0004(\mathrm{n}=10)$ & $0.0001(\mathrm{n}=18)$ & $0.0001(\mathrm{n}=18)$ \\
\hline
\end{tabular}

${ }^{a}$ for difference in change between tomato conditions by group assignment; ${ }^{b}$ for difference in change between tomato conditions by all; N.D. not detectable.

selected from each EC treatment to provide to study participants. The harvested tomatoes were stored under refrigeration $\left(12^{\circ} \mathrm{C}\right)$ until distribution. Randomly selected tomatoes from each feeding cohort were analyzed for nutrient/carotenoid content (Table 1). Briefly, the hexane layer of the extraction solution is removed and measured using a spectrophotometer at $503 \mathrm{~nm}$ (Beckman DU-64, BeckmanCoulter, Fullerton, CA). The total soluble solid concentration was measured by refractometer (AtagoPR-32 $\alpha$, Atago USA, Inc., Kirkland WA) using vacuum extracted juice from the puree filtered through Whatman \#1 filter paper. Additionally, other carotenoids, total phenolics and ascorbic acid concentrations were measured by Brunswick Laboratories (Wareham, MA) and Yuma Agricultural Center Postharvest Physiology Laboratory, from randomly selected tomatoes once per crop for a total of four times throughout the study. The HEC and LEC tomatoes provided mean (SD) lycopene of $62.7 \pm 3.3 \mathrm{mg} / \mathrm{kg}$ and $52.0 \pm 2.4 \mathrm{mg} / \mathrm{kg}$ respectively. Significant differences between tomato groups were demonstrated for lycopene $(P<0.0001), \beta$-carotene $(P<0.0004)$, phenolics $(P<0.0001)$, and ascorbic acid $(P<0.0001)$.

\section{Diet Assessment and Tomato Adherence Measures}

Dietary intake was assessed at baseline and study end using the validated AFFQ [8] where subjects were asked to report intake during the previous 2 month period. Additionally, subjects kept a daily diary of tomato intake during both 3 -week tomato feeding periods including time of day of consumption, amount and preparation methods, plus other food consumed with the tomatoes. Any uneaten tomato portions of tomatoes were returned to the study clinic weekly.

\section{Other Data}

Demographic and lifestyle data were also collected (Table 2). Height, weight, waist:hip circumference, and body composition analysis were assessed at baseline and pre- and post- each feeding period using standardized protocols. These data were used to determine if any changes in BMI or body fat may have occurred potentially influencing lycopene deposition in serum and/or inflammation or oxidative stress biomarker response.

Four 24-hour urine samples were collected after each washout and study intervention period for measurement of the oxidative damage and inflammatory biomarkers. Subjects collected urine at home following standardized procedures and transported the samples on ice to the study clinic where all samples were measured for total volume, gently and thoroughly vortexed, and made into $10-2 \mathrm{ml}$ aliquots for placement in $-80^{\circ} \mathrm{C}$ storage. Twelve hour fasting venous blood samples were collected to assess lipid profiles, carotenoid values, and biomarkers of inflammation. Blood was collected by venipuncture into two 10ml-EDTA, foilwrapped tubes, centrifuged at $4^{\circ} \mathrm{C}$ and $1500 \mathrm{x} \mathrm{g}$ for $10-$ minutes, with serum and plasma aliquoted into $2 \mathrm{ml}$ cryovial samples and stored at $-80^{\circ} \mathrm{C}$.

\section{Biosample Analysis for Carotenoids, Oxidative Stress and Inflammation}

Serum carotenoids were measured by HPLC using previously described procedures [9] to determine changes related 


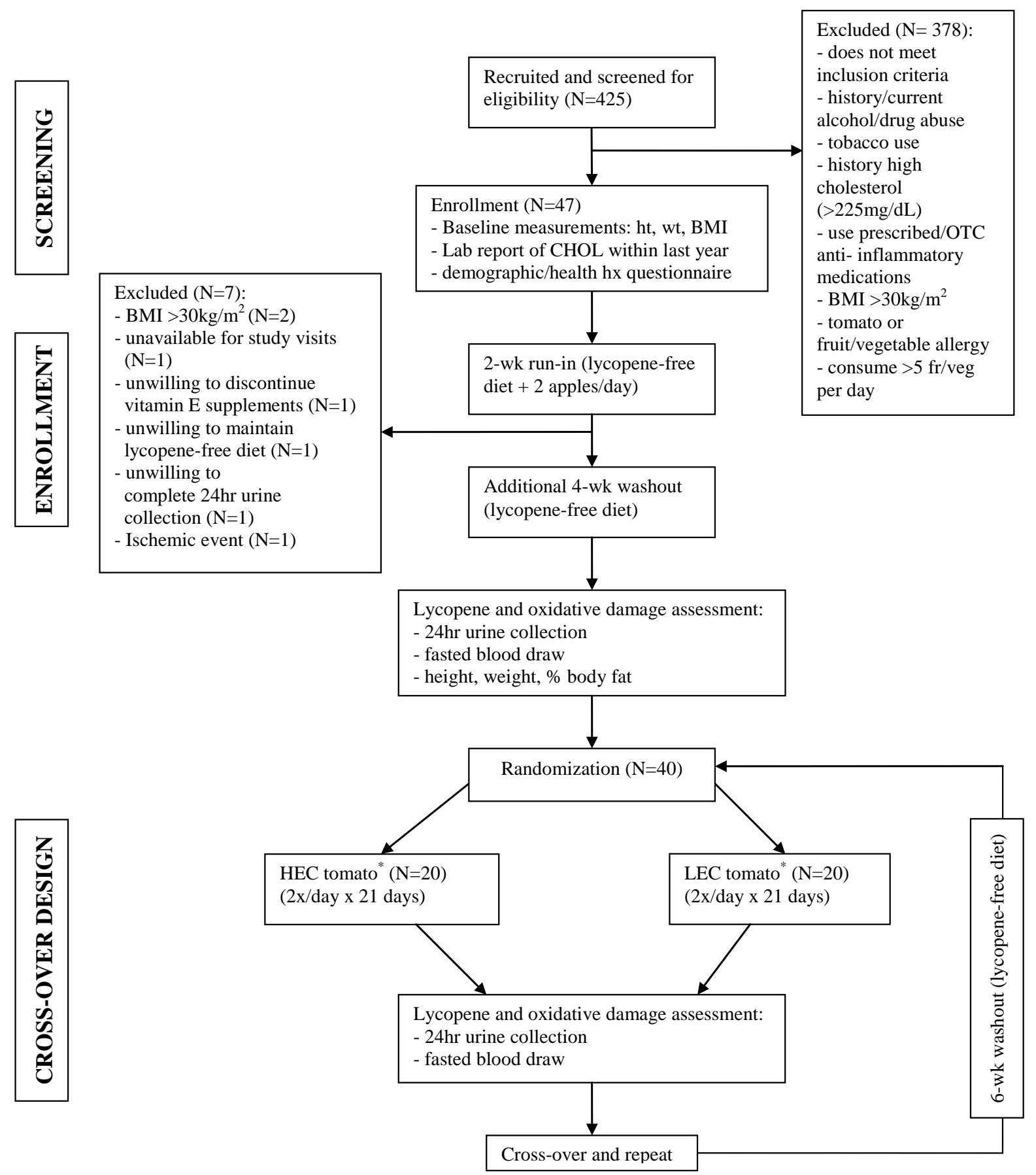

Fig. (1). CONSORT. This diagram illustrates the recruitment, retention, and study measurements collected for the lycopene tomato intervention. ${ }^{*}$ Tomato intake adherence was $98.6 \%$ for both feeding groups.

to tomato exposure. Assessment was performed by Craft Technologies Analytical Laboratory in Cary, NC. The HPLC system consists of a computer data program, an autosampler maintaining samples at $20^{\circ} \mathrm{C}$, a column heater at $31^{\circ} \mathrm{C}$, a programmable ultraviolet visible detector and a fluorescence detector (Thermo Separation Products, Fremont, CA). The $\mathrm{UV} / \mathrm{visible}$ detector was programmed to measure retinol at $325 \mathrm{~nm}$ for 3.75 minutes, then carotenoids at $450 \mathrm{~nm}$ until 5.5 minutes, then tocol at $300 \mathrm{~nm}$ until 6.5 minutes, then carotenoids at $450 \mathrm{~nm}$ until 19.5 minutes, followed by retinol palmitate at $325 \mathrm{~nm}$ until 22 minutes. Linear calibration curves were prepared consisting of three concentrations of analytes which span the physiological levels of micronutrients in serum. The calibrants included lutein, zeaxanthin, $\beta$ cryptoxanthin, lycopene, $\beta$-carotene, $\alpha$-carotene, retinol, and retinol palmitate. Quantification was performed by internal standard calibration using peak area ratios. In-house quality control samples were analyzed at the beginning, end, and at 24 sample intervals with the relative standard deviation of analytes ranging from $3-10 \%$.

Fasting serum high sensitivity C-reactive protein (hsCRP) was measured in triplicate using a highly sensitive 
double antibody sandwich ELISA kit according to the manufacturer's protocol (Diagnostic Systems Laboratories, Webster, TX). Briefly, standards, controls and unknown samples are incubated and washed two times and the degree of enzymatic turnover of the substrate is determined by dual wavelength absorbance measurement at $450 \mathrm{~nm}$. The intra-assay CV was $10.2 \%$.

Table 2. Demographic and Clinical Characteristics of Tomato Study Participants $(n=40)$

\begin{tabular}{|c|c|}
\hline Characteristic & Mean \pm SD or $n(\%)$ \\
\hline \multicolumn{2}{|l|}{ Gender } \\
\hline Males & $15(37.5 \%)$ \\
\hline Females & $25(62.5 \%)$ \\
\hline Age at Study Entry (mean(SD)) & $55.3 \pm 4.7$ \\
\hline \multicolumn{2}{|l|}{ Ethnicity } \\
\hline White & $32(80.0 \%)$ \\
\hline Hispanic & $5(12.5 \%)$ \\
\hline Asian/Pacific Islander & $1(2.5 \%)$ \\
\hline Other & $2(5.0 \%)$ \\
\hline \multicolumn{2}{|l|}{ Education } \\
\hline High School Graduate & $4(10.0 \%)$ \\
\hline Some College & $13(32.5 \%)$ \\
\hline College Graduate/Post-college & $23(57.5 \%)$ \\
\hline \multicolumn{2}{|l|}{ Physical Activity } \\
\hline Seldom or Never & $7(17.5 \%)$ \\
\hline 1-2 Times/Week & $12(30.0 \%)$ \\
\hline 3-5 Times/Week & $15(37.5 \%)$ \\
\hline More than 5 Times/Week & $6(15.0 \%)$ \\
\hline \multicolumn{2}{|l|}{ Current Smoking } \\
\hline Current & $0(0.0 \%)$ \\
\hline Past & $12(30.0 \%)$ \\
\hline Never & $28(70.0 \%)$ \\
\hline \multicolumn{2}{|l|}{ Alcohol Consumption (drinks/day) } \\
\hline None or Less than 1 & $33(82.5 \%)$ \\
\hline $1-2$ & $6(15.0 \%)$ \\
\hline $3-4$ & $1(2.5 \%)$ \\
\hline Height $[\mathrm{cm}]$ & $167.8 \pm 10.2$ \\
\hline Weight (kg) & $71.2 \pm 13.4$ \\
\hline BMI $\left(\mathrm{kg} / \mathrm{m}^{2}\right)$ & $25.1 \pm 3.3$ \\
\hline
\end{tabular}

A competitive ELISA utilizing monoclonal antibody, highly specific for urinary 8-hydroxy-2'-deoxyguanosine and 15-isoprostane $\mathrm{F}_{2 \mathrm{t}}$, was used for quantitative detection of the oxidative DNA damage (8-OHdG Check ELISA kit, No. KOG-200S/E, JaICA, Japan and 8-iso-PGF ${ }_{2 \alpha}$ Oxford Biomedical Research, No. EA85, Oxford, MI, USA). Urine samples were analyzed in triplicate under light-protected conditions according to the manufacturer's instructions. The urinary $8-\mathrm{OHdG}$ and 8 -iso- $\mathrm{PGF}_{2 \alpha}$ concentrations were adjusted to the urinary concentration of creatinine and resulted in intra-assay CV's of $6.9 \%$ and $7.9 \%$, respectively.

\section{Statistical Analysis}

Descriptive statistics of demographic, life style, and body composition characteristics were calculated for the study participants. Spearman correlations were conducted on dietary intake levels of carotenoids, serum carotenoids, 8-isoPGF2- $\alpha, 8-\mathrm{OHdG}$ and hsCRP. T-tests were used to compare: pre- and post-levels of serum carotenoids and oxidative stress factors within experimental tomato assignments; changes in these levels between the LEC and HEC tomato exposures; and differences in carotenoid, phenolics, and ascorbic acid concentrations between LEC and HEC tomatoes within feeding groups. To assess the impact of gender and the two interventions, two period cross-over order, analysis of covariance models were developed including age, $\mathrm{BMI}$, gender as a random effect, and cross-over order as a fixed effect. All analyses were carried out using SPSS 15.0 (SPSS, Chicago, IL). Significance was set at $\alpha=0.05$.

\section{RESULTS}

Fig. (1) describes recruitment, enrollment and retention sample sizes for this research. Selected demographic and lifestyle characteristics are presented in Table 2 . The study population was predominantly female $(62.5 \%)$, white/nonHispanic $(80.0 \%)$ and well educated. The mean age was $55.3 \pm 4.7$ years (mean, SD) and mean BMI was $25.1 \mathrm{~kg} / \mathrm{m}^{2}$ (mild overweight status).

Table 3 presents pre- and post-study intervention levels of select serum carotenoids by tomato type consumed. Both groups demonstrated significant increases in serum total lycopene, trans-lycopene, cis-lycopene, beta-carotene, and total carotenoids when comparing pre- versus post- tomato intervention levels. However, the HEC group exhibited significantly greater increases in serum total lycopene, cislycopene, and beta-carotene $(P=0.05, P=0.03, P=0.02$, respectively), as compared to the LEC group.

Table 4 represents the age and BMI adjusted analysis of change in study biomarkers. No significant changes were demonstrated in $8-\mathrm{OHdG}, 8$-iso-PGF2 $\alpha$ or hsCRP. When gender and crossover models were run, the post hsCRP value for the LEC group was significantly higher than the HEC group $(P<0.001)$ (data not shown).

\section{DISCUSSION AND CONCLUSION}

This randomized, controlled, crossover tomato intervention conducted among healthy adults showed a three-fold and two-fold significant increase in serum trans- and cislycopene concentration, respectively, among participants consuming either LEC or HEC tomatoes twice daily for 3weeks. The rise in cis-lycopene was significantly greater $(\sim 18 \%)$ during HEC feeding than LEC feeding $(P=0.03)$ signifying an enhanced effect on absorption and utilization. This finding is of significant interest to both the consumer and tomato producer in that it suggests tomatoes grown for 
Table 3. Change in Serum Carotenoid Levels of Study Participants During Tomato Feedings $(\mathrm{LEC}, \mathrm{HEC})(\mathrm{mcg} / \mathrm{mL})(\mathrm{n}=40)$

\begin{tabular}{|c|c|c|c|c|c|c|c|c|c|}
\hline & \multicolumn{3}{|c|}{ HEC Tomato } & \multirow[b]{2}{*}{$P^{a}$} & \multicolumn{3}{|c|}{ LEC Tomato } & \multirow[b]{2}{*}{$P^{\mathrm{a}}$} & \multirow[b]{2}{*}{$P^{\mathrm{b}}$} \\
\hline & Pre Level & Post Level & $\Delta$ & & Pre Level & Post Level & $\Delta$ & & \\
\hline Lycopene & $0.13 \pm 0.08$ & $0.32 \pm 0.12$ & $0.19 \pm 0.14$ & 0.0001 & $0.13 \pm 0.09$ & $0.28 \pm 0.11$ & $0.15 \pm 0.14$ & 0.0001 & 0.05 \\
\hline cis-Lycopene & $0.07 \pm 0.03$ & $0.13 \pm 0.04$ & $0.06 \pm 0.05$ & 0.0001 & $0.07 \pm 0.03$ & $0.11 \pm 0.04$ & $0.04 \pm 0.04$ & 0.0001 & 0.03 \\
\hline$\alpha$-Carotene & $0.07 \pm 0.05$ & $0.06 \pm 0.05$ & $-0.01 \pm 0.05$ & 0.42 & $0.07 \pm 0.06$ & $0.07 \pm 0.06$ & $-0.00 \pm 0.05$ & 0.92 & 0.53 \\
\hline$\beta$-Carotene & $0.24 \pm 0.16$ & $0.31 \pm 0.20$ & $0.07 \pm 0.16$ & 0.01 & $0.22 \pm 0.15$ & $0.31 \pm 0.20$ & $0.18 \pm 0.22$ & 0.01 & 0.02 \\
\hline Total Carotenoids & $0.44 \pm 0.22$ & $0.70 \pm 0.32$ & $0.26 \pm 0.27$ & 0.0001 & $0.42 \pm 0.32$ & $0.65 \pm 0.33$ & $0.23 \pm 0.31$ & 0.0001 & 0.60 \\
\hline
\end{tabular}

${ }^{\mathrm{a}}$ for change from pre- to post-intervention within tomato conditions; ${ }^{\mathrm{b}}$ for difference in change between tomato conditions.

Table 4. Age and BMI Adjusted Levels of Urine Oxidative Damage Biomarkers and Blood Serum hsCRP by Tomato Type Consumed by Tomato Study Participants $(\mathrm{ng} / \mathrm{mg})\left(\mathrm{n}=40^{\dagger}\right)$

\begin{tabular}{|c|c|c|c|c|c|c|c|c|c|}
\hline & \multicolumn{3}{|c|}{ HEC Tomato } & \multirow[b]{2}{*}{$P^{\mathrm{a}}$} & \multicolumn{3}{|c|}{ LEC Tomato } & \multirow[b]{2}{*}{$P^{\mathrm{a}}$} & \multirow[b]{2}{*}{$P^{\mathrm{b}}$} \\
\hline & Pre Level & Post Level & $\Delta$ & & Pre Level & Post Level & $\Delta$ & & \\
\hline $\begin{array}{c}\text { 8-Iso-PGF2 } \alpha / \\
\text { Creatinine }\end{array}$ & $4.89 \pm 0.79$ & $5.13 \pm 0.71$ & $0.24 \pm 0.51$ & 0.77 & $5.35 \pm 0.75$ & $4.86 \pm 0.57$ & $-0.49 \pm 0.68$ & 0.66 & 0.45 \\
\hline $\begin{array}{l}\text { 8-OHdg/ } \\
\text { Creatinine }\end{array}$ & $19.69 \pm 3.22$ & $19.33 \pm 3.63$ & $-0.35 \pm 3.17$ & 0.48 & $19.73 \pm 2.96$ & $18.77 \pm 2.76$ & $-0.95 \pm 1.49$ & 0.48 & 0.87 \\
\hline $\mathrm{hsCRP}(\mathrm{mg} / \mathrm{dL})$ & $3.29 \pm 0.43$ & $3.60 \pm 0.63$ & $0.31 \pm 0.51$ & 0.54 & $4.33 \pm 0.72$ & $4.86 \pm 1.24$ & $0.53 \pm 1.28$ & 0.67 & 0.85 \\
\hline
\end{tabular}

${ }^{\dagger} \mathrm{n}=37$ for CRP; ${ }^{\text {a }}$ for change from pre- to post-intervention within tomato conditions; ${ }^{\mathrm{b}}$ for difference in biomarker change between tomato conditions.

enhanced lycopene content favorably affect serum lycopene levels indicating a demonstrated "added market value" of selecting high lycopene tomatoes.

The majority of studies assessing plasma lycopene concentrations after tomato consumption have focused on processed tomatoes or lycopene supplements rather than consumption of fresh tomatoes as evaluated here. In a study by Riso et al. 12 healthy young women consumed tomato products daily ( $\sim 8 \mathrm{mg}$ lycopene/day) according to typical Italian dietary habits for 3 -weeks. Plasma lycopene concentrations were significantly increased post-intervention $(P<0.001)$, however raw tomatoes were only consumed $2 x /$ week, while tomato sauce and tomato paste were consumed 2-3x/week [10]. The present study is distinctive in that we have demonstrated that consumption of two fresh HEC tomatoes daily ( $13.5 \mathrm{mg}$ average lycopene) for 3-weeks is effective in raising total serum lycopene concentrations almost 3-fold above wash-out, an increase comparable to studies using processed or supplemental tomato feeding interventions [11, 12].

Our secondary hypothesis suggesting that regular intake of a HEC tomato would significantly reduce biomarkers of oxidative stress and inflammation as compared to LEC to- mato feeding was not supported by this research. Our results contradict findings of Sánchez-Moreno et al. where 12 healthy adults consumed $500 \mathrm{~mL}$ gazpacho per day for 14days resulting in a significant decrease in 8-iso-PGF2 $\alpha$ [13]. However, plasma lycopene concentration was not measured and thus it is difficult to deduce if these results were due to lycopene. Additional tomato feeding studies have also exhibited a significant decrease in oxidative stess $[11,14]$ although not all $[15,16]$.

Numerous studies have illustrated an inverse association between increased carotenoid intake and inflammatory biomarkers such as hsCRP $[17,18]$. The hsCRP levels of our healthy subjects were below what has been reported among patients diagnosed with cancer [19], and other chronic diseases [20]. Further, a randomized diet study by Jacob et al. in 24 healthy volunteers showed that daily tomato juice consumption was associated with significant reductions in plasma hsCRP [17]. One explanation for the differential response is lycopene dose in that the Jacob's study provided $82 \mathrm{mg}$ lycopene daily and our subjects consumed approximately $13.5 \mathrm{mg}$ lycopene daily. In a study by Blum et al. involving 50 healthy participants consuming $300 \mathrm{~g}$ of fresh 
tomatoes daily for 30 days no change in inflammation was shown, despite a rise in plasma lycopene [21].

To address the limitation of healthy study subjects, this research should be repeated in those demonstrating higher oxidative stress and/or inflammation, such as cancer survivors or obese individuals. Further, the dose of daily lycopene while sufficient to increase serum lycopene levels may have been insufficient to significantly modify these biomarkers. Despite these limitations, this research has significant strengths including the randomized, controlled, crossover design with sufficient wash-out between treatments, testing of efficacy of fresh tomato products and use of recognized biomarkers of oxidative stress and inflammation.

\section{ABBREVIATIONS}

\begin{tabular}{|c|c|c|}
\hline 8-OHdG & $=$ & 8-Hydroxy-2'-deoxyguanosine \\
\hline 8 -iso-PGF $2 \alpha$ & $=$ & 15-Isoprostane $F_{2 \alpha}$ \\
\hline AFFQ & $=$ & Arizona Food Frequency Questionnaire \\
\hline BAFC & $=$ & Bioactive food component \\
\hline BMI & $=$ & Body mass index \\
\hline CVD & $=$ & Cardiovascular disease \\
\hline ELISA & $=$ & Enzyme-linked immunosorbent assay \\
\hline FDA & $=$ & Food and Drug Administration \\
\hline $\mathrm{HEC}$ & - & High lycopene fresh tomatoes \\
\hline HPLC & $=$ & High performance liquid chromatography \\
\hline hsCRP & - & High sensitivity C-reactive protein \\
\hline LEC & $=$ & Standard lycopene fresh tomatoes \\
\hline
\end{tabular}

\section{ACKNOWLEDGMENTS}

The authors would like to acknowledge the laboratory support of Jason Apfel and Georgiana Mitrus for their assistance in carrying out the assays. This research was funded by Bio5, the University of Arizona Institute for Collaborative BioResearch and the Arizona Cancer Center Support Grant CA023074. Funds to support participation-related costs for study subjects were provided by Eurofresh.

\section{REFERENCES}

[1] Arab, L.; Steck, S. Am. J. Clin. Nutr., 2000, 71, 1691S-5S.

[2] Bowen, P.; Chen, L.; Stacewicz-Sapuntzakis, M.; Duncan, C.; Sharifi, R.; Ghosh, L.; Kim, H. S.; Christov-Tzelkov, K.; van Breemen, R. Exp. Biol. Med., 2002, 227, 886-93.

[3] Di Mascio, P.; Kaiser, S.; Sies, H. Arch. Biochem. Biophys., 1989, 274, 532-8

[4] Karas, M.; Amir, H.; Fishman, D.; Danilenko, M.; Segal, S.; Nahum, A.; Koifmann, A.; Giat, Y.; Levy, J.; Sharoni, Y. Nutr. Cancer, 2000, 36, 101-11.

[5] Rafi, M. M.; Yadav, P.N.; Reyes, M. J. Food Sci., 2007, 72, S06974.

[6] Kubota, C.; Thomson, C. A.; Wu, M.; Javanmardi, J. Hort. Sci., 2006, 41, 522-5.

[7] Brown, M.J.; Ferruzzi, M.G.; Nguyen, M.L.; Cooper, D. A.; Eldridge, A. L.; Schwartz, S. J.; White, W. S. Am. J. Clin. Nutr., 2004, 80, 396-403.

[8] Thomson, C.A.; Giuliano, A.; Rock, C.L.; Ritenbaugh, C. K.; Flatt, S. W.; Faerber, S.; Newman, V.; Caan, B.; Graver, E.; Hartz, V.; Whitacre, R.; Parker, F.; Pierce, J. P.; Marshall, J. R. Am. J. Epidemiol., 2003, 157, 754-62.

[9] Peng, Y.; Peng, Y.; Chilers, J.; Hatch, K. D.; Roe, D. J.; Lin, Y.; Lin, P. Cancer Epidemiol. Biomarkers Prev., 1998, 7, 347-50.

[10] Riso, P.; Visioli, F.; Erba, D.; Testolin, G.; Porrini, M. Eur. J. Clin. Nutr., 2004, 58, 1350-8.

[11] Porrini, M.; Riso, P.; Brusamolino, A.; Berti, C.; Guarnieri, S.; Visioli, F. Br. J. Nutr., 2005, 93, 93-9.

[12] Hadley, C.W.; Clinton,.S.; Schwartz, S.J. J. Nutr., 2003, 133, 727 32.

[13] Sanchez-Moreno, C.; Cano, M.P.; de Ancos, B.; Plaza, L.; Olmedilla, B.; Granado, F.; Martin, A. J. Nutr. Biochem., 2006, 17, 1839 .

[14] Rao, L.G.; Mackinnon, E.; Josse, R.G.; Murray, T.M.; Strauss, A.; Rao, A.V. Osteoporos. Int., 2007, 18, 109-15.

[15] Riso, P.; Visioli, F.; Grande, S.; Guarnieri, S.; Gardana, C.; Simonetti, P.; Porrini, M. J. Agric. Food Chem., 2006, 54, 2563-6.

[16] Paterson, E.; Gordon, M.H.; Niwat, C.; George, T. W.; Parr, L.; Waroonphan, S.; Lovegrove, J. A. J. Nutr., 2006, 136, 2849-55.

[17] Jacob, K.; Periago, M.J.; Böhm, V.; Berruezo, G.R. Br J Nutr., 2007, 19, 1-10.

[18] Devaraj, S.; Autret, B.; Jialal, I. Am. J. Clin. Nutr., 2006, 84, 75661.

[19] Uys, A.; Rapoport, B.; Fickl, H.; Meyer, P.W.; Anderson, R. Eur. J. Cancer Care, 2007, 16, 475-83.

[20] Pfutzner, A.; Forst, T. Diabetes Technol. Ther., 2006, 8, 28-36.

[21] Blum, A.; Monir, M.; Khazim, K.; Peleg, A.; Blum, N. Clin. Invest. Med., 2007, 30, E70-4.

(C) Thomson et al.; Licensee Bentham Open.

This is an open access article distributed under the terms of the Creative Commons Attribution License (http://creativecommons.org/licenses/by/2.5/), which permits unrestrictive use, distribution, and reproduction in any medium, provided the original work is properly cited. 